\title{
Studies on the Mechanism of Action of Oxygen-labile Haemolysins
}

\author{
By MARY K. JOHNSON AND KATHRYN S. AULTMAN \\ Departments of Microbiology and Ophthalmology, Tulane University School of \\ Medicine, New Orleans, Louisiana 70112, U.S.A.
}

(Received 14 February 1977)

\begin{abstract}
The sensitivities of the binding step and the lytic step of haemolysis by pneumolysin to the action of various inhibitors and to variations in the assay conditions were studied. Binding was inhibited by $\mathrm{HgCl}_{2}$ and $N$-ethylmaleimide. Lysis by previously fixed lysin was insensitive to $\mathrm{HgCl}_{2}$ and only slightly sensitive to $N$-ethylmaleimide. Binding of pneumolysin was independent of ionic strength. Binding of pneumolysin and streptolysin $\mathrm{O}$ decreased above $\mathrm{pH} 8.0$ and 8.4 , respectively. These results suggest that binding requires a non-ionized unsubstituted sulphydryl group. Incubation of erythrocytes with $\mathrm{NaF}$ caused inhibition of pneumolysin, indicating that some metabolic function of the cell may be involved in lysis. The action of streptolysin $\mathrm{O}$ was not affected by $\mathrm{NaF}$.
\end{abstract}

\section{INTRODUCTION}

Although studies of oxygen-labile haemolysins such as pneumolysin and streptolysin $\mathrm{O}$ have extended over more than 50 years, the basic mechanism by which these agents lyse cells remains unknown. The lytic phenomenon seems to involve two steps, the first being binding of lysin, a process which takes place rapidly even at $0{ }^{\circ} \mathrm{C}$, and the second, a temperature-dependent lysis of the cell (Alouf \& Raynaud, 1968 a). Cholesterol and organic mercurials inhibit pneumolysin (Johnson, I972) and streptolysin O (SLO) (Konbayashi, Hotta \& Koyama, 1972; Oberley \& Duncan, 1971; Smythe \& Harris, I940; Stock \& Uriel, 1961) but only if added before the binding step. It is assumed, therefore, that these agents inhibit binding but not lysis. Lysin must be in the reduced state in order to be bound (Alouf \& Raynaud, 1968b) and this observation, taken with the sensitivity to mercurials, suggests a role for sulphydryl groups in the binding process. Whether these groups actually react with some groups on the cell membrane or merely, in the reduced and unmodified state, contribute to a conformation of the lysin molecule which is appropriate for binding, is not known. We now report the results of further studies of the effects of inhibitors on the binding and lytic steps of the haemolytic process.

\section{METHODS}

Production and titre of pneumolysin. Culture of the type 21 pneumococcal strain, purification of the haemolysin, and determination of haemolysin titre have been described previously (Johnson, 1972). The final concentration of rabbit erythrocytes was such that total lysis yielded a solution with an absorbance at $54 \mathrm{Im}$ of $1 \cdot 0$. One haemolytic unit (H.U.) is defined as the amount of lysin giving $50 \%$ haemolysis in $3 \mathrm{ml}$ standard erythrocyte suspension after $15 \mathrm{~min}$ incubation at $37^{\circ} \mathrm{C}$. Preparations requiring activation with reducing agent were incubated for $30 \mathrm{~min}$ at room temperature with $0.03 \mathrm{M}$ - $\beta$-mercaptoethanol and diluted with phosphate buffered saline (PBS; 0.067 M-potassium phosphate buffer, pH 7.0, with $0.077 \mathrm{M}-\mathrm{NaCl}$ ) containing $0.1 \%(w / v)$ bovine serum albumin (BSA) just before use. Streptolysin $O$ was a crude preparation 'B-D Merieux' obtained from Dr Joseph Alouf of the Pasteur Institute.

All experiments were done in $12 \times 100 \mathrm{~mm}$ test tubes. 
Sulphydryl reagents. Mercuric chloride was studied only in the range 0.2 to $\mathrm{I} \cdot 0 \mu \mathrm{M}$ as higher concentrations were lytic. A lysin preparation which did not require activation by reducing agent was used in these experiments since, even after dilution, an activated preparation would have contained sufficient $\beta$-mercaptoethanol to react with the $\mathrm{Hg}^{2+}$.

In experiments designed to test the effect of $\mathrm{HgCl}_{2}$ added before binding, the reagents were added to tubes in an ice bath in the following order: I.I ml PBS buffer, $0.1 \mathrm{ml} \mathrm{lysin} \mathrm{(I.2} \mathrm{H.U.),} 0.3 \mathrm{ml} \mathrm{HgCl}$ (at a concentration 10-fold higher than the desired final level), and, after $3 \mathrm{~min}, \mathrm{I} \cdot 5 \mathrm{ml}$ erythrocyte suspension. $\left(\mathrm{HgCl}_{2}\right.$ was thus also present during the lytic step.) To examine the effect of the $\mathrm{HgCl}_{2}$ on the lytic step alone, buffer, lysin and erythrocyte suspension were combined and, after $3 \mathrm{~min}, \mathrm{HgCl}_{2}$ was added.

Studies with $N$-ethylmaleimide (NEM) were performed in PBS containing $0.1 \%$ BSA in order to permit prolonged pre-incubation of lysin with NEM at room temperature. The effects of NEM on the two stages of haemolysis were studied separately, as preliminary results showed that both stages were affected. The effect of NEM on binding was studied by incubating $2 \mu \mathrm{l}$ diluted lysin (I.I to $\mathrm{I} \cdot 3 \mathrm{H}$.U.) with $100 \mu \mathrm{l}$ NEM $(0.15$ or $0.3 \mathrm{mM}$ ) for $30 \mathrm{~min}$ at room temperature, then adding $1.4 \mathrm{ml}$ buffer and $\mathrm{I} .5 \mathrm{ml}$ erythrocyte suspension. After $15 \mathrm{~min}$ in the ice bath, the erythrocytes were sedimented and resuspended in $3 \mathrm{ml}$ buffer (PBS with BSA) followed by incubation for $15 \mathrm{~min}$ at $37^{\circ} \mathrm{C}$ to allow action of previously bound lysin. This centrifugation step did not reduce lytic activity in control assays. To study the effect of NEM on lysis only, lysin was subjected to the same pre-incubation (without NEM), combined with buffer and erythrocyte suspension and allowed to stand for $15 \mathrm{~min}$ in ice. Then NEM was added and the suspensions were incubated for $30 \mathrm{~min}$ at room temperature followed by $15 \mathrm{~min}$ at $37^{\circ} \mathrm{C}$. No lysis occurred in control mixtures during the room temperature incubation.

Effects of $\mathrm{pH}$ and ionic strength on binding. Lysin and erythrocytes were incubated in various $0.05 \mathrm{M}-$ glycylglycine buffers containing $0.09 \mathrm{M}-\mathrm{NaCl}$ for $15 \mathrm{~min}$ on ice. The suspensions were then centrifuged and the sedimented cells were resuspended in PBS and incubated for $15 \mathrm{~min}$ at $37^{\circ} \mathrm{C}$. The $\mathrm{pH}$ values of the supernatant fractions were measured. Assays were also performed in PBS of various ionic strengths prepared by adding $\mathrm{NaCl}$. The suspensions were held for $15 \mathrm{~min}$ in an ice bath for binding (using I H.U. of lysin) and then centrifuged, and the cells were resuspended in 'normal' PBS for measurement of lysis at $37^{\circ} \mathrm{C}$.

Fluoride inhibition. The effect of $\mathrm{NaF}$ on haemolysis was determined by pre-incubating the erythrocyte suspension with various concentrations of $\mathrm{NaF}$ at $37^{\circ} \mathrm{C}$ for $5 \mathrm{~min}$, diluting the suspension with an equal volume of PBS at $37^{\circ} \mathrm{C}$, and then adding lysin. At intervals, samples $(3 \mathrm{ml})$ were removed and chilled and the degree of lysis was measured as above. In the experiments in which $\mathrm{NaF}$ was present only during the 5 min pre-incubation period, the suspension was chilled after this period, lysin was added and the suspension was centrifuged. The cells were resuspended in warm PBS, and haemolysis was followed as above.

Data presented are representative of experiments performed at least three times.

\section{RESULTS}

Effect of sulphydryl reagents. To determine the effect on binding and lysis of a mercurial less likely to cause steric hindrance of binding than the organic reagents previously used, inhibition of the reactions by $\mathrm{HgCl}_{2}$ was examined (Table I). The addition of $0.66 \mu \mathrm{M}-\mathrm{HgCl}_{2}$ during binding $(0.33 \mu \mathrm{M}$ final concentration) caused substantial inhibition of pneumolysin, while the presence of as much as $\mathrm{I} \mu \mathrm{M}-\mathrm{HgCl}_{2}$ after binding had no effect. Lysin was substantially inhibited when it was incubated with $0.15 \mathrm{mM}-\mathrm{NEM}$ before binding, and inhibition was complete with $0.3 \mathrm{mM}$-NEM. Some inhibition was observed when NEM was added after binding, but this was incomplete even at $5 \mathrm{~mm}$ (Table 2).

Effects of $\mathrm{pH}$ and ionic strength. Binding of pneumolysin fell off rapidly above $\mathrm{pH} 8$, being almost completely inhibited at $\mathrm{pH} 8 \cdot 4$ (Fig. I). In tests with SLO, the efficiency of binding was considerably decreased above $\mathrm{pH} 8 \cdot 4$. The inhibitory effect of high $\mathrm{pH}$ was not due to inactivation of the lysins, as binding and lysis equal to that of controls took place if the $\mathrm{pH}$ was readjusted to 7 after a period of exposure to a higher $\mathrm{pH}$ (data not shown).

When the ionic strength was increased by 0.2 to 0.6 beyond that in the PBS, no difference in the extent of binding was observed (data not shown).

Inhibition by sodium fluoride. Sodium fluoride inhibited the activity of pneumolysin (Fig.2). Here, the NaF was present during both the pre-incubation and incubation periods, i.e. after addition of lysin. In another experiment in which $\mathrm{NaF}$ was removed after addition of lysin (in the cold), cells lysed at a rate equal to that of the control (lacking NaF). Sodium 
Table I. Effect of $\mathrm{HgCl}_{2}$ on pneumococcal haemolysin

\begin{tabular}{|c|c|c|c|}
\hline \multirow[b]{2}{*}{ System } & \multicolumn{2}{|c|}{$\mathrm{HgCl}_{2}$ present $(\mu \mathrm{M})$} & \multirow[b]{2}{*}{$\begin{array}{c}\text { Haemolysis } \\
(\%)\end{array}$} \\
\hline & $\begin{array}{l}\text { Concn during } \\
\text { binding }\end{array}$ & $\begin{array}{l}\text { Final } \\
\text { concn }\end{array}$ & \\
\hline Control & - & - & 74 \\
\hline $\mathrm{HgCl}_{2}$ added before binding & $\begin{array}{l}0.4 \\
0.66\end{array}$ & $\begin{array}{l}0.2 \\
0.33\end{array}$ & $\begin{array}{l}77 \\
16\end{array}$ \\
\hline & $1 \cdot 0$ & 0.5 & 3 \\
\hline $\mathrm{HgCl}_{2}$ added after binding & - & 0.5 & 75 \\
\hline & - & I. O & 78 \\
\hline Cell control (no lysin) & - & - & 2 \\
\hline Cell control & - & $I \cdot 0$ & 3 \\
\hline
\end{tabular}

Table 2. Effect of $N$-ethylmaleimide on pneumococcal haemolysin

The concentration of NEM shown is that present during pre-incubation of NEM and lysin in part $\mathrm{A}$, and the final concentration in the $3 \mathrm{ml}$ assay in part $\mathrm{B}$.

$\begin{array}{lcc}\text { System } & \begin{array}{c}\text { NEM concn } \\ (\mathrm{mM})\end{array} & \begin{array}{c}\text { Haemolysis } \\ (\%)\end{array} \\ \text { A. Control } & - & 86 \\ \text { NEM added before binding } & 0 \cdot 15 & 23 \\ & 0 \cdot 3 & 3 \\ \text { B. Control } & - & 70 \\ \text { NEM added after binding } & 0 \cdot 1 & 75 \\ & 1 \cdot 0 & 46 \\ & 2 \cdot 0 & 41 \\ \text { Cell control (no lysin) } & 5 \cdot 0 & 32 \\ & 5 \cdot 0 & 1\end{array}$

fluoride was also ineffective if added immediately before or after addition of lysin, i.e. if absent during pre-incubation. No inhibition of lysis was observed when $\mathrm{NaCl}$ was substituted for NaF. With a lower level of lysin (Fig. 3) NaF had less inhibitory effect, manifested primarily in the early part of the incubation period. In erythrocyte suspensions lacking lysin, very little haemolysis took place in the presence or absence of NaF.

With another oxygen-labile lysin, SLO, the effect of NaF was different from that observed with pneumolysin (Fig. 4). Stimulation rather than inhibition of lysis was observed even with higher and lower levels of SLO.

\section{DISCUSSION}

Both pneumolysin (Johnson, 1972) and SLO (Smythe \& Harris, 1940; Stock \& Uriel, I96I) are sensitive to organic mercurials added before binding of lysin to erythrocyte. This sensitivity has been interpreted as reflecting the role of sulphydryl groups in the binding step (Halbert, 1970). However, it is possible that these large molecules might, after reaction with the sulphydryl group, also cover adjacent groups necessary for binding. Another possibility is that lysin binds to the erythrocyte but that the organic mercurial masks a group active in the lytic step. Our results with $\mathrm{HgCl}_{2}$, which would be less likely to block adjacent groups, were similar to those observed with organic mercurials. This would be consistent with the interpretation that the sulphydryl group(s) is indeed involved in the binding step.

The effect of another sulphydryl reagent, the alkylating agent NEM, on the lytic step was investigated by Oberley \& Duncan (1971) using SLO. They reported that addition of I mM-NEM to suspensions of erythrocytes which had already bound lysin produced complete inhibition of haemolysis. When we repeated this experiment with pneumolysin 


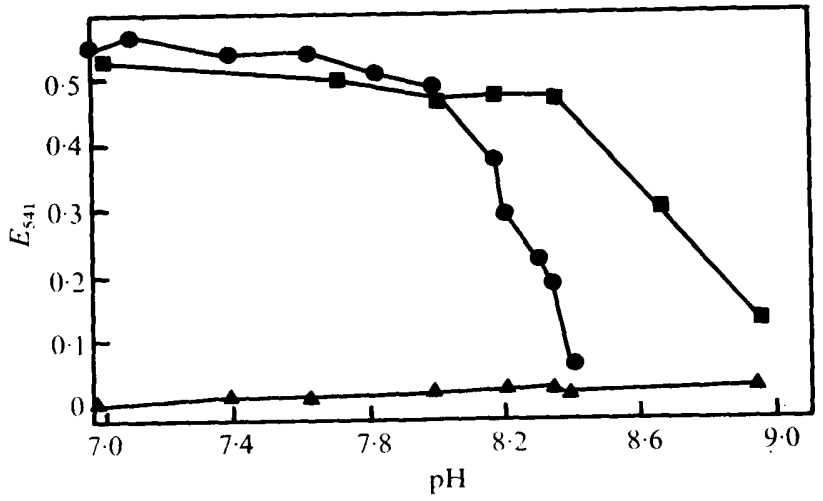

Fig. I. Effect of $\mathrm{pH}$ on binding of pneumolysin and streptolysin $\mathrm{O}: \boldsymbol{\Theta}$, pneumolysin; $\mathbf{\square}$, streptolysin; $\boldsymbol{\Delta}$, erythrocyte control.

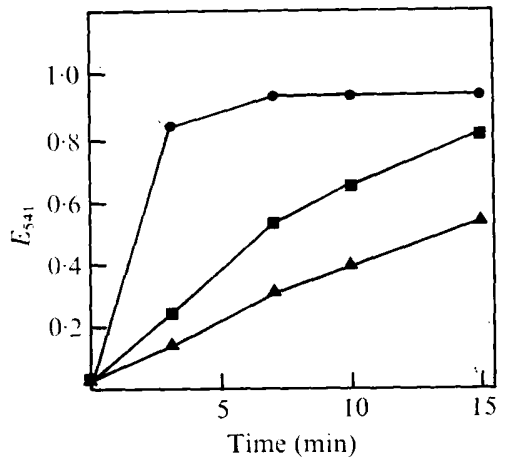

Fig. 2

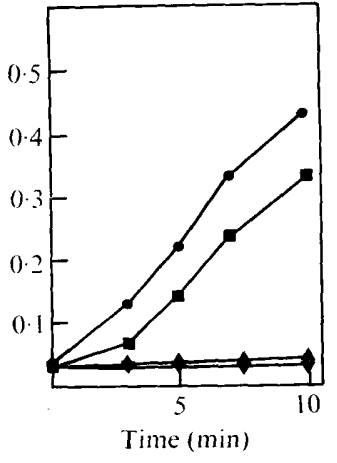

Fig. 3

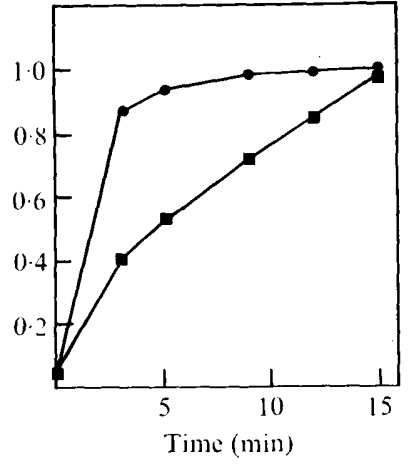

Fig. 4

Fig. 2. Effect of NaF on a high level (3 H.U./3 ml assay) of pneumococcal haemolysin. Erythrocytes were pre-incubated with $\mathrm{NaF}$ for $5 \mathrm{~min}$ before addition or lysin. Final concentration of $\mathrm{NaF}: 0,0 ; \mathbf{Z}, 0.03 \mathrm{M} ; \Delta, 0.05 \mathrm{M}$.

Fig. 3. Effect of NaF on a low level (I H.U./3 ml assay) of pneumococcal haemolysin. Preincubation as in Fig. 2. $\bullet, \mathbf{\square}$, With lysin; $\boldsymbol{\Delta}, \boldsymbol{\nabla}$, no lysin. Final concentration of $\mathrm{NaF}: \boldsymbol{\bullet}, \boldsymbol{\Delta}, 0$; $\mathbf{\nabla}, 0.05 \mathrm{M}$.

Fig. 4. Effect of $\mathrm{NaF}$ on activity of streptolysin $\mathrm{O}(7.5 \mathrm{H} . \mathrm{U} . / \mathrm{I} 5 \mathrm{ml}$ assay). Pre-incubation as in Fig. 2. Final concentration of NaF: $\mathbf{1}, 0 ; 0,0.05 \mathrm{M}$.

(Table 2), we found inhibition to be incomplete even at $5 \mathrm{mM}$. At these high levels, NEM might affect groups other than sulphydryls, such as histidine residues. However, our experiments with NEM added before binding showed complete inhibition of haemolysis at $0.3 \mathrm{mM}$, demonstrating the greater sensitivity of the binding step.

The question remains whether the sulphydryl group involved in binding actually reacts with a site on the erythrocyte membrane or merely must be reduced and unsubstituted in order to provide a conformation of the lysin molecule which is appropriate for the binding process. Studies of the effect of $\mathrm{pH}$ on binding with pneumolysin (Johnson, 1972) and SLO (Oberley \& Duncan, 197I) have shown no effect up to $\mathrm{pH} 8$. However, as the $\mathrm{p} K_{\mathrm{a}}$ of cysteine is 8.3 and it could conceivably be shifted to an even higher value in the microenvironment of the cysteine residue in the protein, we examined the effects of higher $\mathrm{pH}$ on binding. It was found (Fig. 2) to fall off rapidly above pH 8.0 (8.4 for SLO), which is consistent with a role for the sulphydryl group in the non-ionized state. 
Oberley \& Duncan (197I) suggested that cholesterol may be involved in a hydrophobic interaction between the lysin and membrane and that this constitutes the binding process. Consistent with this suggestion, they found the binding of SLO to be independent of ionic strength. We have found that this is also true for pneumolysin.

The mechanism by which lysis occurs after fixation of lysin to the membrane is unknown. Enzymic action of SLO or pneumolysin has not been demonstrated. We considered the possibility that lysis results from the effect of lysin on some metabolic process of the erythrocytes which is concerned, directly or indirectly, with osmotic stabilization. Our finding (Figs 2 and 3) that NaF inhibits haemolysis by pneumolysin if present during both the preincubation and incubation periods appears to support this hypothesis. The possibility that $\mathrm{NaF}$ acts by preventing binding was ruled out since cells lysed in a normal fashion when $\mathrm{NaF}$ was removed after pre-incubation and fixation of lysin. We are aware of no other report of fluoride inhibition of the activity of an isolated haemolytic agent, but Ramm \& Winkler (I973) have reported fluoride inhibition of the rickettsial (whole cell) haemolytic system.

The fact that lysis by SLO was stimulated rather than inhibited by fluoride suggests that there may be some differences in the mechanism of action. The similarities in binding properties of the two lysins (i.e. sensitivity to cholesterol and mercurials, insensitivity to ionic strength, and similar responses to $\mathrm{pH}$ ) may reflect similarities of their binding sites. The differences noted in the properties of the lytic step (in response to NEM and to fluoride) may reflect differences in a lytic site. This would be consistent with the partial immunological identity reported (Todd, 1934) for the two proteins.

This work was supported by Public Health Service Grant EY-00424 from the National Eye Institute.

\section{REFERENCES}

Alouf, J. E. \& RAYNAUD, M. (1968a). Action de la Streptolysine $O$ sur les membranes cellulaires. I. Fixation sur la membrane erythrocytaire. Annales de l'Institut Pasteur I14, 81 2-827.

Alouf, J. E. \& Raynaud, M. (I968 b). Action de la Streptolysine $O$ sur les membranes cellulaires. II. Cinétique de la lyze erythrocytaire. Annales de l'Institut Pasteur Ir5, 97-I 2 I.

HALBERT, S. P. (1970). Streptolysin O. In Microbial Toxins, vol. 3, pp. 69-98. Edited by T. C. Montie, S. Kadis and S. A. Ajl. New York: Academic Press.

JoHnson, M. K. (1972). Properties of purified pneumococcal hemolysin. Infection and Immunity 6, 755-760.

Konbayashi, Y., Hotta, M. \& Koyama, J. (1972). Kinetic study on Streptolysin O. Journal of Biochemistry 7r, 227-237.

Oberley, T. D. \& Duncan, J. L. (197I). Characteristics of Streptolysin $\mathrm{O}$ action. Infection and Immunity 4, 683-687.
RAMM, L. E. \& WINKLER, H. H. (I973). Rickettsial hemolysis: effect of metabolic inhibitors upon hemolysis and adsorption. Infection and Immunity 7, 550-555.

SMYTHe, C. V. \& Harris, T. N. (1940). Some properties of a hemolysin produced by group $\mathbf{A} \beta$ hemolytic streptococci. Journal of Immunology 38, 283-300.

STOCK, A. H. \& URIEL, J. (I96I). Electrophoretic mobility and detection of hemolytic activity of streptolysins $\mathbf{O}$ and $\mathbf{S}$ in agar gel. Nature, London I92, 435-436.

ToDD, E. W. (1934). A comparative serological study of streptolysins derived from human and from animal infections, with notes on pneumococcal haemolysin, tetanolysin and staphylococcus toxin. Journal of Pathology and Bacteriology 39, 299-32I. 